\title{
Antecedentes y perspectivas sobre periodismo literario español durante el siglo XX
}

\author{
Juan-Francisco Torregrosa CARMONA \\ Universidad Rey Juan Carlos de Madrid \\ juanfrancisco.torregrosa@urjc.es \\ Carmen GaOna PisOnero \\ Universidad Rey Juan Carlos de Madrid \\ carmen.gaona@urjc.es
}

\section{Resumen}

El presente texto se ocupa de una parcela de la Comunicación en la Historia, cual es el llamado periodismo literario durante el siglo XX. En este campo no existe sólo el legado de los autores anglosajones sino que también en España ha habido muestras relevantes.

Palabras clave: Periodismo - Literatura - Prensa española - Siglo XX

\section{History and perspectives on Spanish literary journalism during the XXth century}

\begin{abstract}
This paper deals with a plot of Communication in History, which is called literary journalism in the twentieth century. In this field there is not only the legacy of the Anglo-Saxon authors but also in Spain has been relevant samples.
\end{abstract}

Key Words: Journalism - Literature - Spanish Newspapers - Twentieth century

\section{Referencia normalizada:}

Torregrosa Carmona, J. F.; Gaona Pibonero, C. (2013) Antecedentes y perspectivas sobre periodismo literario español durante el siglo XX. Historia y Comunicación Social. Vol. $18 \mathrm{~N}^{\circ}$ Especial Octubre. Págs. 789-798.

Sumario: 1. Introducción. El contexto del periodismo y la literatura en España durante el siglo XX. 2. Metodología. 3. Antecedentes sobre periodismo literario. El Nuevo Periodismo. 4. Perspectivas sobre el periodismo literario y narrativo en español durante el siglo XX y en la actualidad. 5. Conclusiones. Referencias bibliográficas. 


\section{Introducción. El contexto del periodismo y la literatura en españa durante el siglo $\mathrm{XX}$}

En 1845 ya preguntó Joaquín Francisco Pacheco a los miembros de la Real Academia Española " ¿Es verdaderamente el periodismo una rama fecunda de la literatura?”. (Rodríguez Rodríguez y Angulo Egea, 2010) Hoy, como a lo largo del siglo XIX, la cuestión sigue suscitando encontradas opiniones doctrinales y no existe unanimidad al respecto.

Se ha dicho que el periodismo y la literatura son como la rama y el tronco que no pueden vivir por separado. Quienes han estudiado la literatura en el periodismo y el periodismo en la literatura, justifican la necesidad de seguir profundizando en el conocimiento de las relaciones entre ambas formas de expresión (Asís Garrote, 1997. Pág. 449):

"Si todavía sigue en vigor aquella división clásica entre la información de actualidad y el relato de acontecimientos, y el juicio que provocan tales acontecimientos -periodismo de información/periodismo de opinión, división establecida en todos los manuales, que después se complica, a la hora de estudiar qué sea el artículo- hoy, cuando en literatura y también en periodismo asistimos a la ruptura de los géneros, se hace necesario el estudio de la evolución de la escritura periodística, al menos en algunas de las modalidades que se van afirmando".

En esta introducción cabría diferenciar tres etapas del siglo XX, en periodos aproximados de un tercio, respecto a las relaciones entre la literatura y el periodismo (de 1898 a 1936, de 1939 a 1975 y de 1976 a 2001). Sin embargo, por seguir la estructura de los principales especialistas, las dejaremos en dos: de la crisis de fin de siglo a las vanguardias y de 1936 a la actualidad. Así es como lo configura la editora María del Pilar Palomo (1997), cuya obra de referencia titulada Movimientos literarios y periodismo en España seguimos en todo momento en este apartado.

Por lo que tiene que ver con la primera etapa, marcada por el modernismo y el novecentismo en el contexto de la citada crisis finisecular, destacan nombres de autores tan diversos como Rubén Darío, Miguel de Unamuno, Ángel Ganivet, Antonio Machado, Valle-Inclán, Pío Baroja, Juan Ramón Jiménez o el caso de José Martínez Ruiz, Azorín, y su conocida vinculación con periódicos tan señeros y longevos, todavía hoy vivos, como $A B C$, pero también La Vanguardia, entre otros, incluso de América Latina, a los que tuvo acceso por la fama que llegó a alcanzar, caracterizada por rasgos personales como su firme voluntad de estilo.

Acosta Montoro (1973, Pág. 145) considera a Unamuno, Azorín y Baroja, “columna vertebral, aunque no exclusiva, de un periodismo que influyó poderosamente en su sociedad y que, desde luego, la movió a cambio".

Otro autor de primera línea que cultivó el periodismo fue José Ortega y Gasset, a partir de géneros como la crónica de viajes:

"Todas las crónicas de viaje de Ortega están escritas en la primera mitad del siglo $\mathrm{XX}$. Son unos textos incardinados en la producción viajera de la generación del 
98, que a su vez nos llega ligada a la del siglo XIX, y ésta a la remota de los siglos XVII y XVIII. Nos encontramos con un género literario y periodístico que se nutre en gran medida del costumbrismo. Los viajes se convierten en oportunidades para que el viajero describa no sólo un paisaje, un pueblo, un escenario, una cultura, sino también para dejar hablar a las gentes que lo habitan, a mostrarse con sus costumbres y usos" (Blanco Alfonso, 2011. Pág. 59).

La nómina del periodismo y la literatura en la segunda fase que se ha señalado, durante los primeros años de la posguerra, nos deja, por su parte, sin ánimo de exhaustividad en la lista, firmas tan relevantes como las de José María Pemán, César González-Ruano o Josep Plá.

La narrativa de posguerra cuenta con autores que, con mayor o menor intensidad, aportaron textos al periodismo e incluso vivieron en buena medida de él. Es el caso, en distintos registros, de Álvaro Cunqueiro, Arturo Barea y Max Aub, entre otros.

Un buen ejemplo de llegada a la cima de la literatura desde el periodismo profesional en el siglo XX español lo representa quien fuera director del periódico El Norte de Castilla y autor de excelentes obras como El camino o Las ratas: Miguel Delibes. También cultivó los más diversos géneros periodísticos, en el diario argentino La Nación, el longevo Francisco Ayala, autor de títulos como Muertes de perro o La cabeza del cordero.

Contra lo que piensan algunos, las relaciones entre periodismo y literatura son plenamente bidireccionales, pues como destaca Albert Chillón, el peso creciente de la industria de la comunicación en la cultura contemporánea es sin duda uno de los factores que ha impulsado la redefinición del canon literario tradicional (1999. Pág. 61):

"La industria periodística, en concreto, ha transformado las pautas de producción, consumo y valoración social de la literatura: por un lado, contribuyendo a la formación de géneros nuevos -así, la novela realista del XIX o el costumbrismo periodístico-literario de Dickens, Larra o Vilanova-; por otro, impulsando el desarrollo y la difusión de géneros literarios de carácter testimonial, como la prosa de viajes y el memorialismo; en último lugar generando modos singulares de escritura periodística -reportaje, crónica, ensayo, columna y artículo, guion audiovisual- que, en ciertos casos al menos, han alcanzado un alto valor artístico, hasta el punto de influir en la fisonomía de las formas literarias tradicionales".

\section{Metodología}

La revisión bibliográfica y hemerográfica constituye el eje central del presente trabajo. Se parte de la evidencia de las relaciones que existen entre periodismo y literatura, entre los géneros literarios y los informativos. De hecho, algunos autores incluso asocian el cuento con la crónica periodística y la novela con el reportaje en profundidad. Esta última comparación ha sido especialmente relevante a lo largo de la historia, como habrá ocasión de comprobar en las siguientes líneas. 
Como complemento metodológico, nos servimos de la encuesta realizada a veintisiete alumnos y alumnas de la asignatura Literatura Española del Curso de Formación para el Acceso a la Universidad de Mayores de 25 años, en la Universidad Rey Juan Carlos (curso académico 2011-2012).

Pese a no poder contar con unos resultados muy representativos, dada la limitación de la muestra, sí se puede obtener alguna pista acerca del conocimiento o la popularidad de la materia y de sus representantes más conocidos.

Los estudiantes identificaron como ejemplos de autores que cultivan el periodismo literario actual a Juan José Millás, en primer lugar, y a continuación a Manuel Vicent y a Maruja Torres. Del pasado reciente citaron a Francisco Umbral y a Manuel Vázquez Montalbán. En todos los casos, se trató de respuestas abiertas, en las que no estaba sugerido nombre alguno.

Entre las fuentes para el estudio de este ámbito, consideramos de especial interés, por su carácter pionero y su acreditada solvencia, el texto de José Acosta Montoro, Periodismo y literatura (1973). Otras obras más recientes que constituyen también ejemplos de investigación de calidad sobre la materia que abordamos son las de Albert Chillón (1999), Literatura y periodismo. Una tradición de relaciones promiscuas, y la coordinada por María del Pilar Palomo (1997), Movimientos literarios y periodismo en España.

Del mismo modo, en 2010 se publicó la obra Periodismo literario. Naturaleza, antecedentes, paradigmas y perspectivas, coordinada por José Miguel Rodríguez Rodríguez y María Angulo Egea. Esta obra constituye uno de los últimos acercamientos teóricos a la materia y sirve también como apoyo al ámbito que estamos estudiando en esta contribución.

\section{Antecedentes sobre periodismo literario. EI nuevo periodismo}

Hay que remontarse bastante atrás para encontrar los orígenes del periodismo en la literatura y de la literatura en la prensa.

Esa constatación proviene de otra: las implicaciones entre la literatura y el periodismo han sido las características de una "tradición de relaciones promiscuas" (Chillón, 1999). Y con razón se ha afirmado así. Porque esos vínculos notables se pueden apreciar tanto en la etapa decimonónica como en el siglo veinte español, en una realidad que por supuesto no resulta exclusiva de nuestro entorno más cercano, sino que se puede comprobar en muchos otros lugares.

En especial, ha resultado relevante a lo largo de la Historia del Periodismo Universal el movimiento del llamando "Nuevo periodismo", que en el ámbito anglosajón alumbraron autores como Tom Wolfe, uno de los representantes más conocidos. Precisamente Wolfe está considerado entre los grandes pioneros de este movimiento, 
junto con Gay Talese. Se trata de un fenómeno surgido hacia la mitad de la década de los sesenta que consiguió convulsionar el panorama literario norteamericano. Destacaron muchos otros autores, como Rex Reed, Terry Southern, Nicholas Tomalin, Barbara L. Goldsmith, Norman Mailer, Joe McGinnis o John Gregory Dune.

Para Tom Wolfe, lo que se hizo fue arrebatar el centro a la agonizante y esterilizada novela para que el periodismo se convirtiera en el género literario más rico de la época. Los periodistas se sumergían en los lugares y los ámbitos donde ocurrían los acontecimientos, hacían preguntas arriesgadas y entraban en contacto con los más completos desconocidos. Otra consecuencia del movimiento fue el retorno a la gran novela realista que habían visto alumbrar los siglos precedentes.

Es bien conocido que la situación en España por aquella época seguía marcada por el letargo cultural de la dictadura franquista. Sin embargo, las figuras de periodistas-escritores y escritores-periodistas pueden atisbarse en el caso español desde bien temprano.

En el siglo XVIII parecen contraponerse dos posturas en nuestro país, la ilustrada y la tradicionalista, la última de las cuales sigue apegada a la concepción barroca del arte y vuelve la mirada a modelos como los que representaron Góngora y Quevedo, Lope y Calderón (Palomo, 1997. Pág. 53).

Durante el siglo XIX, con una prensa marcada por la exaltación política, pero también por la crítica literaria y por el costumbrismo (Mesonero Romanos y Mariano José de Larra, principalmente, si bien en los orígenes de la obra de ambos se observan diferencias); junto con la prensa periódica más convencional, verán la luz un buen número de colecciones literarias y de revistas de creación artística e incluso de divulgación científica e investigadora. Además del romanticismo, habrá otras corrientes y movimientos literarios y periodísticos, tales como el realismo y el naturalismo.

Uno de los hombres más importantes del periodismo es Mariano de Cávia, 18551920 (Angulo Egea y Leal Bonmati, 2008. Pág. 11 y pág. 17).

Será no obstante en el siglo XX, con la mayor difusión de las publicaciones, cuando exista una eclosión de la presencia de la literatura en la prensa informativa de actualidad, aunque con considerables diferencias entre los diferentes tercios (de 1898 a 1936, de 1939 a 1975 y de 1976 a 2001, aproximadamente). Y es que las radicalmente distintas situaciones políticas y sociales se impondrán también en este campo. En todo caso, en todas las décadas del pasado siglo ya había una presencia de autores relevantes con el doble perfil de dedicación simultánea al periodismo y a la literatura, como en la etapa decimonónica pero con el mayor desarrollo de la prensa y el más amplio acceso popular a la misma en el nuevo siglo.

Como muestra del interés que suscita hoy el llamado Nuevo Periodismo, se puede mencionar la reciente aparición en español del libro La banda que escribía torcido. Una historia del Nuevo Periodismo (2013), de Marc Weingarten, obra cuyo título original es The gang that wouldn't write straight. 


\section{Perspectivas sobre el periodismo literario y narrativo en español durante el siglo XX y en la actualidad}

El periodismo literario -que otros autores llaman periodismo narrativo, denominación más común en América Latina frente a la primera, predominante en Europadebe ser entendido "no como la literatura publicada en los periódicos y las revistas (las obras ficticias o poéticas), sino como un macrogénero que, bajo otros géneros, agrupa un conjunto de textos que son al mismo tiempo Periodismo y Literatura" (Rodríguez Rodríguez y Angulo Egea, 2010. Pág. 268).

Hemingway aseguraba que "la novela moderna es un gran reportaje periodístico". Uno de los máximos exponentes universales de tal afirmación está considerada la obra A sangre fría, de Truman Capote. No obstante, su autor aseguraba que la obra que había escrito no era periodismo, sino que había inventado un nuevo género literario: "la novela de no-ficción" (Wolfe, 1976. Pág. 57).

Tom Wolfe considera que las mismas objeciones que saludaron a la novela en los siglos XVIII y XIX se empezaron a hacer al Nuevo Periodismo. El escritor aclara: "La condición de la novela era tan baja... bueno, era tan baja como la condición del periodismo de revista cuando Truman Capote empezó a publicar A sangre fría en The New Yorker" (Wolfe, 1976. Pág. 58).

Albert Chillón (1999) recuerda, por su parte, que el periodismo y la novela moderna tuvieron un nacimiento coetáneo. Es Daniel Defoe quien publica en 1722 el primer reportaje novelado que se conoce, A Journal of the Plague Year (Diario del año de la peste), una reconstrucción detallada de la epidemia de peste bubónica que sufrió Londres en 1665.

En el caso del panorama español, Camilo José Cela, Gonzalo Torrente Ballester, Antonio Gala o Carmen Martín Gaite son solamente algunos de los nombres de quienes realizaron un trabajo que se puede considerar como periodismo literario.

Cultivaron diversos géneros periodísticos, desde el artículo de prensa y el ensayo hasta el diario personal. Pese a su variedad de estilos, temas y visiones, todos ellos aparecen unidos por la característica común de la calidad en el dominio del lenguaje, con un conocimiento certero tanto del registro plenamente literario, asociado a la novela o al cuento, como del periodístico, más propio de la actualidad informativa diaria.

En los últimos decenios del pasado siglo los lectores españoles de prensa disfrutaron con la extraordinaria pluma de figuras como Francisco Umbral o Manuel Vázquez Montalbán, como hoy lo hacen de otras como Manuel Vicent, Rosa Montero, Antonio Muñoz Molina, Javier Marías, Manuel Rivas o Juan José Millás, por citar sólo unos pocos entre los más sobresalientes. Algunos de estos mismos nombres fueron citados por los alumnos encuestados mediante preguntas abiertas (Curso de Acceso a Mayores de 25 años mencionado en el apartado de Metodología). 
En el momento actual se está produciendo un notable auge del llamado periodismo narrativo. Destacan hoy diversos nombres de periodistas de América Latina que demuestran un dominio sin fisuras del género de la crónica, a modo de híbrido entre la información periodística y la literatura. Son muchos los ejemplos. Uno de ellos, con muchos seguidores en el extenso ámbito de la lengua española, el de Leila Guerriero. Y qué decir de los consagrados maestros como Gabriel García Márquez (Premio Nobel de Literatura en 1982) o del también premio Nobel de Literatura Mario Vargas Llosa. Ambos se encuentran por méritos indudables en la nómina de los más grandes autores contemporáneos dentro de la creación no sólo literaria sino también periodística. En el caso de Vargas Llosa, mediante géneros como el artículo de prensa, en particular. Este autor ha asegurado: "Muchos de mis libros yo no hubiera podido escribirlos sin el periodismo", al tiempo que considera: "El periodismo ha sido una actividad fundamental que ha alimentado en buena parte mi obra literaria".

Por lo que tiene que ver con Europa en su conjunto, uno de los considerados grandes maestros del periodismo narrativo fue el reportero polaco Ryszard Kapuscinski, desaparecido en 2007. Chillón (1999) ha estudiado, como grandes referencias del periodismo narrativo y literario, a autores de indiscutible valía como Daniel Defoe, Charles Dickens, Thomas de Quincey, Ernest Hemingway, John Dos Passos, Josep Pla, James Agee y Lillian Ross, y más recientes como Truman Capote, John Hersey, Gay Talese, Tom Wolfe, Oriana Fallaci, Gabriel García Márquez, el propio Kapuscinski, o españoles como Eduardo Haro Tecglen, Manuel Vázquez Montalbán, Maruja Torres o Manuel Vicent. A esta lista añaden otros analistas a Joseph Mitchell, Tomás Eloy Martínez y Rodolfo Walsh (Tijeras, 2013). Otros prosistas y periodistas que merecen estar en esa lista son Leonardo Sciascia, Eduardo Galeano o Günter Walrraff, "el periodista indeseable" autor de investigaciones y reportajes memorables.

Al igual que el estadounidense, también existió un "nuevo periodismo" español, pese a que no contara con una figura central, como la que ocupaba el ya citado TomWolfe en el caso americano (Chillón, 1999. Pág. 352):

"Desde finales de los años sesenta y hasta los primeros ochenta, coetáneamente a la eclosión y la proliferación de los nuevos periodismos en Europa y en Estados Unidos se desarrolló en España una corriente periodístico-literaria marcada, entre otras cosas, por una actitud de acento crítico e intelectual, heredada de la mejor tradición periodística española. La nueva corriente, integrada en su mayor parte por autores nacidos en los años treinta, cuarenta y los primeros cincuenta, recibió un fuerte impulso durante el ocaso del franquismo y los primeros compases de la transición, al amparo de las importantes mudanzas que estaba experimentando la prensa escrita del país".

Revistas como Destino, Triunfo, Cuadernos para el Diálogo, Hermano Lobo, Cambio 16, Interviu, La Calle o El Viejo Topo son dignas de mención, así como los siguientes periódicos, entre otros: Informaciones, Madrid, Diario 16, La Vanguardia y, sobre todo, El País. Y periodistas como los ya mencionados Manuel Vázquez Montalbán, Francisco Umbral, Manuel Vicent o Maruja Torres, que, al igual que algunos otros, llevaban años ensayando innovaciones cuando en 1976 apareció la 
traducción castellana de El nuevo periodismo, la célebre antología de textos de Tom Wolfe (Chillón, 1999. Pág. 353).

Más allá de las etapas recordadas, queda fuera de toda duda que en los últimos tiempos se está asistiendo a un nuevo empuje del llamado periodismo narrativo. Lejos quedan los años sesenta y el Nuevo Periodismo norteamericano, que rompe a conciencia la división tradicional entre escritura de ficción y escritura de no ficción, al combinar el verismo documental propio del periodismo y los métodos de la literatura convencional. Sin embargo, no es menos cierto que las nuevas tecnologías, particularmente Internet, las mezclas y la relativa difuminación entre los géneros y las formas expresivas más tradicionales son factores que alumbran un nuevo paso de madurez en el cruce de caminos siempre inacabado -en constante renovación- entre periodismo y literatura.

\section{Conclusiones}

Una vez estudiada la relación entre expresión periodística y literaria, se constata que la Historia del Periodismo español no ha sido ajena a la fecunda tradición universal de relación e implicaciones mutuas entre ambas manifestaciones socioculturales: periodismo y literatura.

Junto con la presencia de escritores-periodistas y de periodistas que han realizado exitosas incursiones en los diversos géneros literarios, principalmente la novela, ha habido un periodismo literario como tal, con grandes nombres a lo largo del siglo XX español.

La doctrina señala cómo el enriquecimiento proviene de ambas orillas de la creación mediante la palabra. Aunque Balzac consideró en su tiempo que el periodista era la subespecie del hombre de letras, no pocos autores han reconocido al periodismo y a la literatura como los dos brazos de un mismo río.

De hecho, si algunas de las mejores páginas de la literatura vieron por primera vez la luz en la prensa periódica, tampoco se puede pasar por alto la influencia de la propia prensa en los movimientos literarios imperantes durante el pasado siglo.

El llamado periodismo narrativo o literario cuenta con grandes ejemplos en la literatura y el periodismo inglés y norteamericano. Sin embargo, en España también ha habido sobresalientes autores que han cultivado este campo y otros que igualmente lo hacen en las revistas y los periódicos actuales con indiscutible éxito, pero también con indiscutible calidad.

Algunos de los autores del periodismo literario español del siglo XX resultan bien conocidos, tanto o más por su obra periodística que por la literaria, dado que son, por lo general, profesionales con una amplia presencia en los medios de comunicación 
de diversa naturaleza, lo que ofrece popularidad a su figura y amplía los ecos de un trabajo brillante en el periodismo y en la literatura del tiempo actual.

Cabe mencionar como autores reconocidos por el público lector de prensa, entre otros, a Millás o Vicent, como lo fueron en épocas recientes Umbral o Vázquez Montalbán, ya desaparecidos pero con una obra tanto periodística como literaria vasta y de gran valor. Una obra que contribuye a incrementar el notable acervo del patrimonio hemerográfico español.

Junto a los columnistas y reporteros españoles mencionados, como ejemplo de convivencia armoniosa entre los registros estilísticos de la literatura y del periodismo, sobresale hoy igualmente el cultivo de la crónica latinoamericana.

\section{Referencias bibliográficas}

ACOSTA MONTORO, José (1973): Periodismo y literatura. Madrid: Ediciones Guadarrama.

ANGULO EGEA, María y LEAL BONMATI, María del Rosario. (2008). Edición crítica de Azotes y galeras, de Mariano de Cávia. Zaragoza: Asociación de la Prensa de Aragón.

ASÍS GARROTE, María Dolores (1997): Periodismo y literatura en la segunda mitad del siglo XX, en PALOMO, María del Pilar (1997): Movimientos literarios y periodismo en España. Madrid: Síntesis.

BLANCO ALFONSO, Ignacio (2011): Estructura y composición de una crónica de viaje de José Ortega y Gasset, en BLANCO ALFONSO y FERNÁNDEZ MARTÍNEZ: Entre la ficción y la realidad. Perspectivas sobre periodismo y literatura. Madrid: Fragua.

CHILLÓN, Albert (1999): Literatura y periodismo. Una tradición de relaciones promiscuas. Barcelona: UAB.

PALOMO, María del Pilar (1997): Movimientos literarios y periodismo en España. Madrid: Síntesis.

RODRÍGUEZ RODRÍGUEZ, Jorge Miguel y ANGULO EGEA, María, coords. (2010): Periodismo literario. Naturaleza, antecedentes, paradigmas y perspectivas. Madrid: Fragua.

TIJERAS, Ramón (2013): Periodismo narrativo y no ficción. Comunicación 21. Revista Vivat Academia, $\mathrm{n}^{\mathrm{o}} 3$. Disponible en: http://www.counicacion21.com/ periodismo-narrativo-y-no-ficcion/ [12-07-2013].

WEINGARTEN, Marc (2013). La banda que escribia torcido. Una historia del Nuevo Periodismo. Madrid: Los libros del K.O.

WOLFE, Tom (1976): El nuevo periodismo. Barcelona: Anagrama. 


\section{Los autores}

Juan-Francisco Torregrosa Carmona. Doctor por la Universidad Complutense de Madrid en Ciencias de la Información (sobresaliente cum laude). Profesor Titular de Periodismo en la Universidad Rey Juan Carlos, en la que imparte docencia desde 2004. Licenciado en Periodismo y Licenciado en Derecho. Autor de numerosas publicaciones, su último libro es Redacción periodística. Los estilos y los géneros informativos e interpretativos en la prensa (2013). Durante años trabajó como periodista en medios y gabinetes de empresas privadas y de la Administración Pública. Ha impartido conferencias y docencia sobre Comunicación en universidades públicas y privadas de Europa, América y Asia (universidades de Pekín y Waseda University, de Tokio).

Carmen Gaona Pisonero. Doctora por la Universidad de Barcelona (UB) en Sociología. Profesora Contratada Doctora de Periodismo en la Universidad Rey Juan Carlos, desde 2006. Colaboró con la Facultad de Geografía e Historia de la UB y con la Facultad de Ciencias Sociales de la Universidad Católica San Antonio de Murcia (UCAM). Licenciada en Antropología Social y Diplomada en Comercio Exterior. Ha sido profesora invitada en centros como la Universidad de Amiens, la Universidad de Bicocca (Milán), el LabComplex(UNAM-México), Universidad de Estrasburgo y Universidad de Oporto. Su línea de investigación se ha centrado en cuatro temas prioritarios: Inmigración, Antropología Urbana, Salud, y Ciberpatologías en población infantil. 